\title{
Functional Foods in fad diets: A review
}

\section{Daniela Abigail Navaro'; Olga Raz ${ }^{1}$; Sharon Gabriel ${ }^{1}$; Vered Kaufman Shriqui ${ }^{1}$; Esther Gonen ${ }^{1}$, Mona Boaz ${ }^{1,2}$.}

${ }^{1}$ Department of Nutrition Sciences, Ariel University, (Ariel), Israel; ${ }^{2}$ Epidemiology and Research Unit, E. Wolfson Medical Center, (Holon), Israel

Corresponding Author: Mona Boaz, PhD, Professor, Chair, Department of Nutrition Sciences, Ariel University, Kvish 36, Ariel, 40700, Israel

Submission Date: March 18th, 2017, Acceptance Date, September 27th, 2017, Publication Date: September 30th, 2017

Citation: Navaro D.A., Raz O., Gabriel S., Shriqui V.K., Boaz M., Functional Foods in Fad Diets: A Review. Functional Foods in Health and Disease 2017; 7(9); 702-715.

https://doi.org/10.31989/ffhd.v7i9.346

\begin{abstract}
Fad diets can be defined as any diet making claims that are unrealistic and not supported by evidence-based data. Having been developed since the early $19^{\text {th }}$ century, fad diets promise drastic weight loss and/or other unsubstantiated health claims while often omitting entire food groups. Their popularity with the public makes them an important topic for nutritionists and clinicians, especially in the framework of the obesity epidemic. Additionally, it is conceivable that components of fad diets can indeed facilitate weight loss, even if the diet overall is without merit. The grapefruit diet, the cabbage soup diet, and the human chorionic gonadotropin (hCG) diet are among the most popular fad diets and are reviewed within this study not only in terms of the diet plan itself, but also in terms of possible and known weight loss and health benefits provided by the foods on which the diets are based. Bioflavonoids in grapefruit, including naringin, hesperidin, and bergamottin, may benefit glucose homeostasis. Cabbage contains lutein, zeaxanthin, kaempferol, quercetin, and apigenin, which have anti-inflammatory properties and improve both glucose homeostasis and fat metabolism. The hCG diet is frequently supplemented with non-hCG preparations often containing African mangoes, which has been shown to enhance weight loss by an unspecified mechanism; astragalus root, which has antioxidant, anti-inflammatory, and peroxisome proliferator-activated receptor-gamma receptor agonistic properties; arginine, which stimulates lipolysis; glutamine, which has been shown to enhance weight loss, perhaps by altering the gut microbiome; carnitine, which appears to facilitate weight loss; B12, which improves insulin resistance; and niacin, which improves the dyslipidemia associated with being overweight/obese. Presently, high-quality clinical trials suggest that fad diets reduce weight in the short term due to drastic caloric restriction rather than functional food properties. However, the proof of principle has been demonstrated, and clinical trials of the functional foods utilized in fad diets are much needed.
\end{abstract}

Keywords: functional foods, fad diet, weight loss, naringin, hesperidin, and bergamottin 


\section{INTRODUCTION}

Globally, obesity prevalence has risen steeply between the years 1980 to 2000, in both adults and children [1-5]. Today, obesity prevalence remains unacceptably high: almost $70 \%$ of US adults are overweight or obese, defined as a body mass index (BMI) of $\geq 25 \mathrm{~kg} / \mathrm{m}^{2}$ [6]. Of these, more than $30 \%$ are considered obese $\left(\mathrm{BMI} \geq 30 \mathrm{~kg} / \mathrm{m}^{2}\right)$ and more than $6 \%$ are extremely obese $(\mathrm{BMI} \geq 40$ $\mathrm{kg} / \mathrm{m}^{2}$ ). Just as distressing is the high prevalence of obesity (defined as BMI above the age and sex-specific $85^{\text {th }}$ percentile of the Centers for Disease Control and Prevention or World Health Organization growth charts) among children aged 2-19 years, which is as high as 30\% in some countries [7]. Almost $17 \%$ of U.S. children are obese, defined as BMI above the age and sexspecific $95^{\text {th }}$ percentile of the same growth charts [3].

Being overweight or obese are conditions not exclusive to developed nations; in fact, overweight and obesity prevalence has soared in developing countries, creating the double healthcare burden of non-communicable diseases associated with obesity on the one hand and infectious diseases and malnutrition on the other [4]. In developed countries, a massive diet industry has been spawned by the increase in overweightness/obesity prevalence, which was estimated to have reached \$61 billion in the US alone in 2014 [8].

Weight reduction interventions within the consensus of medical professions range from lifestyle interventions, the most efficacious of which include caloric restriction, increased physical activity, and behavioral changes [9], to pharmaceutical interventions [10] to bariatric surgery [11]. Additionally, a parallel "fad diet" industry has arisen.

A "fad diet" can be described as any diet making claims that are unrealistic and not supported by evidence-based data [12]. Other frequent characteristics of fad diets include emphasis on a certain food or food group, omission of certain foods or food groups, claims of drastic weight loss (> $1.5 \mathrm{~kg} /$ week), and other health claims [13].

Fad diets are not a new phenomenon. The market for weight loss diets arose with industrialization during a time during where food became a market commodity [14]. In the early $19^{\text {th }}$ century, poet Lord Byron advocated vinegar as a remedy for obesity, claiming it reduced his appetite; however, it has been suggested that the romantic author suffered from anorexia [15]. An early version of a fad diet can be seen in the writings of Jean Brillat-Savarin, who blamed refined flour and starch for obesity and in 1825 recommended a low-carbohydrate, high-protein diet for weight loss [15]. In 1863, William Banting published "Letter on Corpulence Addressed to the Public." In this treatise, Banting counseled the overweight to omit sugar, starch, fat, and beer from their diets [16]. Perhaps the most dangerous fad diet was the "smoking diet" which was made famous in the early $20^{\text {th }}$ century, in which at least one tobacco company marketed cigarettes to women as a means of controlling body weight [15].

Neither the safety nor the long-term efficacy of fad diets is supported in scientific evidence. However, scientific and clinical communities should not ignore this phenomenon. The public continues to utilize these diets in an attempt to control body weight, oblivious to the potential health damage they may incur through these diets. In fact, these diets do result in short-term weight loss, as any calorie restriction would do. It is reasonable for nutritionists, biochemists, physicians, and food scientists to familiarize themselves with some of the more popular of these fad diets in order to understand their basis and to properly advise the public. 
The Grapefruit Diet: Description

The Grapefruit Diet has been present in the United States since the early $20^{\text {th }}$ century. At the time, proponents of the diet claimed that enzymes or some other component in grapefruit possessed a "fat burning" property. However, this enzyme was not identified [17].

A typical meal plan for this diet includes the following [15]:

- Breakfast: half of a grapefruit or $200 \mathrm{ml}$ unsweetened grapefruit juice, a cup of tea or black coffee, 2 eggs and 2 slices of bacon

- Lunch and dinner: half of a grapefruit or $200 \mathrm{ml}$ unsweetened grapefruit juice, $200 \mathrm{~g}$ meat, poultry or fish cooked as desired, unlimited "non-starchy" vegetables, black coffee or tea

Some versions of the diet allow for an additional $200 \mathrm{ml}$ vegetable juice and/or skim milk to be consumed during the day.

This is a very low-calorie, low-carbohydrate diet. Depending on the version of the diet followed, it may provide as few as $800 \mathrm{kcal} /$ day.

\section{Bioactive Qualities of Grapefruit}

Grapefruit (citrus paradise) is a natural hybridization of pomelo and orange belonging to the large Rutaceae family of citrus [19].

Grapefruit is relatively low in calories (less than $50 \mathrm{kcal} / 100 \mathrm{~g}$ ), being high in pectin, an insoluble fiber that, in large amounts, is capable of laxative qualities [20]. These qualities may explain the weight loss properties attributed to grapefruit. Additionally, grapefruit provides large amounts of vitamin C, vitamin A, and antioxidants lycopene in pink grapefruit, beta carotene, xanthin, and lutein. Grapefruit, together with other citrus fruits, have been shown to possess highly active antioxidant activity on several assays [21].

Additional bioactive compounds in grapefruit include flavonoids - especially naringin and hesperidin, furanocoumarins, in addition to bergamottin and 6'7'-dihydroxybergamottin [22-24].

Citrus-derived flavonoid supplementation has been shown to improve insulin sensitivity and to prevent hepatic steatosis and dyslipidemia, apparently via inhibition of hepatic fatty acid synthesis together with increased fatty acid oxidation [25]. Furthermore, citrus flavonoids have been shown to attenuate the inflammatory response in adipose tissue and in the liver, thereby having the potential benefit to treat and prevent obesity, diabetes, hypertension, and metabolic syndrome [26, 27].

One of the most important citrus bioflavonoids is naringenin, which occurs in both an aglycone and glycoside form. Naringenin has been shown to participate in carbohydrate metabolism; specifically, naringenin has been shown to inhibit gluconeogenesis from lactate plus pyruvate, alanine, and dihydroxyacetone [28]. In vitro studies have demonstrated that naringenin participates in the induction of peroxisome proliferator-activated receptors (PPAR)-regulated fatty acid oxidation genes, including Cytochrome P450 4A11 (CYP4A11) and uncoupling protein 1 (UCP1) while inhibiting liver X receptor (LXR) alpha-regulated lipogenesis genes, such as the first apoptosis signal (FAS) gene. The net result of this effect is the increased cholesterol production coupled with increased fatty acid oxidation [29].

Obese cats were fed a diet supplemented with a combination of naringenin and hesperidin in one arm of a crossover study. Reductions in plasma acute phase protein and peripheral blood 
mononuclear cell interferon (INF)-gamma levels suggest that these polyphenols could ameliorate the inflammatory state associated with obesity [30].

Because dietary polyphenols including bergamot have been shown to reduce nonalcoholic fatty liver disease (NAFLD), its use was studied in a rat model of pediatric metabolic syndrome and NAFLD. Indeed, drinking water supplemented with bergamot curtailed obesity and blunted increased blood glucose and triglyceride levels in these cafeteria diet fed rats. Significantly, NAFLD was prevented, apparently by stimulating lipophagy [31]. In a small study with human subjects, supplementation with a combination of polyphenols including bergamot was associated with improved lipid profile and reduced oxidative stress; however, a decline in body weight was not observed [32].

In a study designed to investigate interventions for insulin resistance, male Wistar rats fed a high fat and sucrose diet were assigned to supplementation with helichrysum extract, grapefruit extract or no supplementation (controls). Rats supplemented with either grapefruit or helichrysum extract exhibited less insulin resistance, oxidative stress, and inflammation, in addition to gaining less body weight than controls [33].

\section{Human Studies}

In a randomized clinical trial, obese adults with no comorbidities were instructed to consume a calorie restricted diet and either $1 / 2$ grapefruit, one glass of unsweetened grapefruit juice, or bottled water 20 minutes before each meal. Weight loss did not differ significantly between groups at the end of follow-up, nor did any anthropometric measures [17]. All three groups lost approximately $7 \%$ of the baseline body weight, indicating that pre-meal satiating strategies can be an effective weight loss strategy.

In contrast, a clinical trial conducted in 91 obese adults found greater weight loss among subjects exposed to grapefruit or grapefruit products than placebo [34]. The study randomized participants to one of four interventions: 1) $207 \mathrm{ml}$ of apple juice plus placebo capsules (control); 2) grapefruit capsule plus $207 \mathrm{ml}$ apple juice; 3) $237 \mathrm{ml}$ grapefruit juice plus placebo capsule; 4) $1 / 2$ fresh grapefruit with a placebo capsule. Interventions were consumed prior to every meal. At the end of the 12-week follow-up, subjects with the metabolic syndrome exposed to grapefruit in any format (capsules, juice or fresh fruit) lost significantly more weight than participants in the control condition.

Consistent with these results, citrus polyphenolic extract including grapefruit extract was found to increase fat loss in a 12-week, randomized, placebo-controlled clinical trial in overweight adults [35].

\section{The Cabbage Soup Diet: Description}

As the name suggests, the cabbage soup diet permits an unlimited intake of cabbage soup. A number of variations on the cabbage soup recipe have been publicized, but most of these recipes include, in addition to cabbage, onions, tomatoes or tomato juice, celery, and carrots.

The 7-day meal plan for the cabbage soup diet permits unrestricted cabbage soup intake together with combinations of foods that are claimed to facilitate and maximize weight loss [36]:

- Day 1: cabbage soup and raw fruit but not bananas 
- Day 2: cabbage soup and raw or cooked vegetables but not potatoes

- Day 3: cabbage soup and raw fruit and vegetables but not bananas or potatoes

- Day 4: cabbage soup, skim milk, and as many as eight bananas

- Day 5: cabbage soup, six tomatoes, and 565g beef.

- Day 6: cabbage soup, unlimited beef, and unlimited vegetables (excluding potatoes)

- Day 7: cabbage soup, brown rice, and sugar-free fruit juice

The diet provides much less than $1000 \mathrm{kcal} /$ day on Days 1-3, about 1000 or slightly more on Days 4 and 7, and more than $1200 \mathrm{kcal}$ on Days 5 and 6. Though exercise is discouraged on this diet, a weight loss of $4.5 \mathrm{~kg} /$ week or more is promised [36].

\section{Bioactive Qualities of Cabbage}

The cabbage soup recipes used in this diet plan are based on white (rather than red) cabbage. According to the United States Department of Agriculture (USDA) National Nutrient Database [37], $100 \mathrm{~g}$ shredded white cabbage provides $23 \mathrm{kcal}, 1.9 \mathrm{~g}$ fiber, and $1.3 \mathrm{~g}$ protein. Cabbage is rich in vitamin $\mathrm{C}$, providing $38 \mathrm{mg}$, or $41-50 \%$ percent of the Recommended Dietary Allowance (RDA); and vitamin K, providing $110 \mathrm{mcg}$, which or $60-67 \%$ of the RDA. A $100 \mathrm{~g}$ serving of white cabbage also contains lutein and zeaxanthin $(27 \mathrm{mcg})$ in addition to flavonoids kaempferol $(1.2 \mathrm{mg})$, quercetin $(3.9 \mathrm{mg})$, and apigenin $(0.04 \mathrm{mg})$ [38].

In an animal model of non-alcoholic fatty liver disease (NAFLD), supplementation with lutein resulted in a reduction of fat mass but not body weight in rats that were fed a high-fat diet. Lipid profile was improved, perhaps through the increased peroxisome proliferators activated receptor alpha and sirtuin expression. Insulin sensitivity was also improved with an increased expression of insulin receptor substrate-2, phosphatidylinositol 3-kinase, and glucose transporter-2 at both gene and protein levels (39). Zeaxanthin produced anti-inflammatory effects by inhibiting nuclear factor kappa B (NF- $\kappa \mathrm{B})$ activity and restoring inhibitor kappa B alpha (I $\mathrm{B}-\alpha)$, and while this was demonstrated in an animal model of alcoholic fatty liver disease, the protein expression of NF- $\kappa \mathrm{B}$ inhibitor I $\mathrm{KB}-\alpha$ has been shown to be lower in aorta from obese mice, suggesting a role for inflammation in the pathogenesis of chronic diseases associated with obesity; furthermore, NF- $\kappa \mathrm{B}$ inhibition has been associated with the reduced expression of several pro-inflammatory proteins, many of which are elevated in obesity [40-42].

Obesity has been characterized by low-grade, chronic inflammation [43]. It is through the inhibition of several inflammatory pathways that the flavonoid kaempferol, which is abundant in white cabbage, may be beneficial in treating obesity. Inflammatory mechanisms inhibited by kaempferol include expression of interleukin (IL)-1 beta and tumor necrosis factor by lowering messenger RNA (mRNA) transcription of these cytokines [44], suppression of tumor necrosis factor (TNF) -induced IL-8 promoter activation and gene expression [42], and inhibition of the Janus kinase (JAK)3 signaling pathway, which inhibits IL-4 and IL-2 mediated outcomes [45].

The flavonoid quercetin, which is also abundant in white cabbage, has been shown to improve insulin resistance and glucose tolerance and to reduce body weight, specifically, body fat, in rats fed a high-fat diet [46]. Quercetin produced weight and visceral fat loss in another animal model, associated with reduced lipid accumulation in adipocytes together with increased carnitine palmitoyltransferase $1 \alpha$ mRNA expression but decreased PPAR- $\gamma$ and CCAAT/enhancer binding 
protein in adipose tissue [47]. In another model of the high fat diet in mice, intraperitoneal injections of rutin, the glycoside of quercetin, was shown to inhibit the anticipated increase in adipocyte size. Weight and fat mass gain was prevented without accompanying changes in lean body mass or food intake. Additionally, rutin treatment was associated with improved glucose tolerance and insulin sensitivity together with reduced blood insulin levels [48].

On the other hand, mice fed a high fat diet and supplemented with either $0.05 \%$ or $0.1 \%$ quercetin did not exhibit reduction in body weight; however, both dose groups showed an increase in lean body mass. Only the lower dose group showed reduction in epididymal fat. These changes were accompanied by reduced markers of inflammation [49]. Similarly, quercetin did not reduce body weight or fat mass, but did improve serum glucose homeostasis in mice fed a high fat, high sucrose diet for six weeks [50].

Another bioactive flavonoid found in white cabbage is apigenin, which has been shown to act as a PPAR $\gamma$ activator and modulator. Apigenin-activated PPAR $\gamma$ decreases NF- $\kappa \mathrm{B}$ activation. In an obese mouse model, apigenin decreases pro-inflammatory cytokines, reducing inflammatory cell infiltration in both the liver and adipose tissue. This improves glucose tolerance and reduces the overall inflammatory response associated with obesity [51].

Obese mice were fed a high-fat diet with or without apigenin supplementation. Apigenin supplementation was associated with improved lipid profile and markers of liver function, though neither food intake nor body composition was changed. Additionally, apigenin was associated with reduced blood glucose levels, improved glucose balance, and lower levels of pro-inflammatory markers [52].

\section{Human Studies}

No randomized clinical trials of the cabbage soup diet or of cabbage have been reported in medical literature as of 2017. In a pilot study, participants were randomized to dietary enrichment with a specially prepared fruit/vegetable drink or a commercially available vegetable juice that included cabbage extract. The specially prepared fruit/vegetable drink was superior to the commercial vegetable juice in terms of normalizing the lipid profile; however, subsequent analysis revealed that superiority had in fact not been shown $[53,54]$. Change in body weight or composition was not reported in this study.

In early work on the satiety index, the cabbage soup diet was cited as an example of including a high-satiety, low-calorie food source to produce weight reduction [55]. However, the ability of this diet to produce weight loss compared to an isocaloric alternative has not been demonstrated.

\section{The HCG Diet: Description}

Frohlich's Syndrome, also known as adiposogenital dystrophy, is a rare metabolic disease associated with hypothalamic tumors, which may increase appetite and depress gonadotropin secretion. Consequently, this disorder is characterized by obesity and growth retardation, with impaired development of the genitalia [56]. Endocrinologist ATW Simeons treated patients with this syndrome with intramuscular injections of human chorionic gonadotropin (hCG). He noted that this treatment resulted in a reduction in fat mass and a change in fat distribution, even in cases where weight loss was not achieved. This observation appears to have inspired him to test this treatment in otherwise healthy obese adults. Using a very low calorie diet (500 kcal/day) together 
with daily hCG injections (125 IU/day), Simeons reported great success in achieving weight loss in his subjects, noting that fat mass was reduced without loss of lean body mass [57]. Interestingly, subsequent studies have not been able to duplicate the hCG-associated weight loss reported by Simeons [58].

While there are many versions of this diet, menu plans typically divide food intake into two meals. At lunch the dieter consumes 100 grams of a low-fat protein (chicken breast, fish, turkey, etc.), one serving of a vegetable, one fruit, and a serving of starch. This meal is repeated at dinner [59].

Legitimately used in assisted fertility, hCG has not been approved by the US Food and Drug Administration (FDA) for weight loss. In fact, the FDA, together with the Federal Trade Commission, have issued a warning that over the counter HCG products marketed as weight loss aids are unproven and illegal. These organizations have jointly issued warning letters to companies illegally marketing over-the-counter hCG products labeled for weight loss [60]. Despite this, a variety of hCG preparations, some of which are crude or degraded and some of which actually contain very little or no hCG, are marketed to the public for weight loss. These preparations can be administered via intramuscular or subcutaneous injection, but some offer oral or nasal administration [61].

Some of the non-hCG preparations include the African mango or its extract (Irvingia gabonensis). This supplement has been identified as a popular supplement for weight loss [62]. In a systematic review of African mango for weight reduction, three randomized clinical trials were identified, all of which observed significantly greater weight loss in treated vs. untreated individuals; however, the study quality was poor, precluding recommendation of this supplement for the treatment of obesity [63]. The astragalus root is also found in many non-hCG preparations, and has antioxidant, anti-inflammatory, and PPAR-gamma receptor agonistic properties which may improve insulin sensitivity and glucose homeostasis [64]. Both animal models and in vitro studies have shown that astragalus root is associated with improved measures of metabolic control, including normalized levels of glucose, insulin, and blood lipids. Furthermore, astragalus root has been shown to attenuate leptin resistance [65].

Arginine and glutamine are amino acids frequently included in some non-hCG preparations. A stimulator of lipolysis, L-arginine participates in the oxidation of fatty acids to $\mathrm{CO} 2$ and water by increasing PPAR-gamma coactivator-1 alpha (PGC-1 alpha) expression. Lipid metabolism and energy balance are further acted upon by L-arginine via increased 5' adenosine monophosphate (AMP)-activated protein kinase (AMPK) expression and activity. Significantly, dietary arginine supplementation has been shown to reduce white adipose tissue in a number of animal models and in obese humans with type 2 diabetes. Animal studies have shown that supplementation with Larginine is associated with reduced perigonadal fat deposits and improved glucose homeostasis compared to mice fed an isocaloric diet. This was observed despite the relative hyperphagia observed in the arginine-supplemented animals, suggesting a significant decrease in feed efficiency together with increased energy expenditure [66, 67]. Glutamine supplementation has been shown to enhance weight loss in overweight or obese women, accompanied by a nonsignificant 20-\% decrease in hyperinsulinemia [68]. It is possible that one mechanism through which glutamine enhances weight loss is by altering the gut microbiome. In a short-term pilot study in which overweight or obese adults were randomized to supplementation with glutamine or 
alanine, subjects in the glutamine group exhibited alterations in the composition of gut microbiota. Significantly, there was a significant decrease in the Firmicutes:Bacteroidetes ratio, a biomarker associated with weight loss [69].

Perhaps due to its role in fat metabolism, carnitine is often included in non-hCG preparations. A large meta-analysis including data for more than 900 human subjects indicates that carnitine can significantly facilitate weight loss. Compared to controls, carnitine supplemented subjects lost approximately $1.33 \mathrm{~kg}$ and $0.47 \mathrm{~kg} / \mathrm{m} 2 \mathrm{BMI}$ from baseline measures [70].

Two B-vitamins, B12 and niacin, are frequently listed as ingredients in non-hCG preparations. In a large cross-sectional analysis in white British women at the $28^{\text {th }}$ week of pregnancy, inverse associations between blood levels of vitamin B12 and both BMI and markers of insulin resistance were observed [71]. However, this association cannot be interpreted as causal because exposure and outcome were measured simultaneously.

Niacin is also frequently included in no-hCG supplements. While niacin has been shown to benefit the dyslipidemia often associated with obesity, its role as an anti-obesity intervention is less clear. Metabolic syndrome patients were assigned to treatment $1500 \mathrm{mg}$ extended-release niacin or a placebo. Niacin was associated with a $56 \%$ increase in adiponectin together with a $27 \%$ increase in leptin, but no changes in measures of inflammation or endothelial function were observed; in fact, glucose homeostasis deteriorated [72]. Niacin-induced pancreatic islet dysfunction may be modulated through the activation of the islet beta-cell G-protein-coupled receptor, (GPR) 109a-induced pathways involving reactive oxygen species, PPAR-gamma and uncoupling protein (UCP) 2 pathways [73]. Niacin supplementation has been shown to stimulate the expression of genes involved in carnitine uptake and to replenish depleted carnitine levels in obese rats, presumably via PPAR-activation [74].

\section{Human Studies}

A systematic review of randomized clinical trials comparing the hCG diet identified 12 studies of good methodological rating. One reported that $\mathrm{HCG}$ was a useful adjunct while the remaining 11 did not detect a benefit of hCG treatment beyond the calorie restriction inherent in the diet. Superior weight loss, fat distribution, hunger, or wellbeing did not differ between hCG-treated patients and controls [75]. There appears to be little evidence for the efficacy of hCG as treatment for obesity [76].

\section{CONCLUSION}

There are a number of mechanisms through which substances in food specific fad diets might contribute to efficacy. Flavonoids such as naringenin and bergamot in grapefruit, kaempferol in cabbage and the amino acids arginine and glutamine (frequently included in non-hCG preparations) improve glucose homeostasis. Quercetin in cabbage and astragalus in non-hCG preparations have anti-inflammatory properties. Thus, a "proof of principle" has been identified for a number of these bioactive ingredients. However, long term randomized clinical trials of good quality are necessary to demonstrate the efficacy of these diets independent of caloric restriction. Identifying bioactive ingredients with high efficacy in facilitating weight reduction would permit the use of these products in the framework of safe and adequate dietary patterns. Until such studies are available, it would be prudent to encourage overweight or obese individuals to consume varied 
and nutritious diets in accordance with accepted guidelines to facilitate prudent weight loss. In conclusion, the weight reduction achieved by fad diets is achieved primarily by drastic calorie restriction rather than the phytochemicals presented in food. Nevertheless, because functional foods used in these diets are conceivably useful in weight reduction, high-quality randomized clinical trials are needed to examine their efficacy in weight reduction in overweight/obese humans.

List of Abbreviations: AMP, 5' adenosine monophosphate; AMPK, AMP-activated protein kinase; CYP4A11, Cytochrome P450 4A11; FAS, First apoptosis signal; hCG, human chorionic gonadotropin; IL, Interleukin; INF, Interferon; JAK, Janus kinase; LXR, Liver X receptor; mRNA, messenger RNA; PGC1-alpha, Peroxisome proliferator-activated receptors (PPAR-gamma) coactivator-1 alpha; PPAR, Peroxisome proliferator-activated receptors; TNF, Tumor necrosis factor; UCP1, Uncoupling protein 1; UCP2: Uncoupling protein 2

Authors' Contributions: M Boaz and A Navaro conceived of and designed the review. M Boaz, O Raz S Gabriel, and V Kaufman-Shriqui participated in drafting the manuscript. E Gonen reviewed the manuscript and all authors were engaged in the manuscript work. M Boaz and A Navaro have primary responsibility for the final content. All authors have read and approved the final manuscript.

Competing Interests: None of the authors have competing interests to declare.

Acknowledgements and Funding: There is no funding to declare.

\section{REFERENCES}

1. Stevens GA, Singh GM, Lu Y, et al.: National, regional, and global trends in adult overweight and obesity prevalences. Population Health Metrics 2012, 10:22.

2. The GBD 2013 Obesity Collaboration, Ng M, Fleming T, et al.: Global, regional and national prevalence of overweight and obesity in children and adults 1980-2013: A systematic analysis. Lancet 2014, 384:766-781.

3. Ogden CL, Carroll MD, Fryar CD, Flegal KM: Prevalence of obesity among adults and youth: United States, 2011-2014. NCHS Data Brief 2015, Nov (219):1-8.

4. Ogden CL, Carroll MD, Lawman HG, Fryar CD, Kruszon-Moran D, Kit BK, Flegal KM: Trends in obesity prevalence among children and adolescents in the United States, 19881994 through 2013-2014. JAMA 2016, 315:2292-9.

5. Hruby A, Hu FB: The Epidemiology of Obesity: A Big Picture. PharmacoEconomics 2015, 33:673-689.

6. Wang Y, Beydoun MA: The obesity epidemic in the United States--gender, age, socioeconomic, racial/ethnic, and geographic characteristics: a systematic review and meta-regression analysis. Epidemiol Rev 2007, 29:6-28.

7. Jones RE, Jewell J, Saksena R, Ramos Salas X, Breda J. Overweight and Obesity in Children under 5 Years: Surveillance Opportunities and Challenges for the WHO European Region. Front Public Health 2017, 5:58. 
8. La Rosa J: The U.S. Weight Loss \& Diet Control Market. FL: Marketdata LLC; 2017.

9. Baetge C, Earnest CP, Lockard B, Coletta AM, Galvan E, Rasmussen C, et al.: Efficacy of a randomized trial examining commercial weight loss programs and exercise on metabolic syndrome in overweight and obese women. Appl Physiol Nutr Metab 2017, 42:2 16-227.

10. Semla TP, Ruser C, Good CB, Yanovski SZ, Ames D, Copeland LA, et al.: Pharmacotherapy for Weight Management in the VHA. J Gen Intern Med 2017, 32(Suppl 1):70-73.

11. Vidal J, Corcelles R, Jiménez A, Flores L, Lacy AM: Metabolic and Bariatric Surgery for Obesity. Gastroenterology 2017, 152:1780-1790.

12. Freedman MR, King J, Kennedy E: Executive Summary. Obesity Research 2001, 9: 1S$5 \mathrm{~S}$.

13. Bryngelsson S, Asp NG: Popular diets, body weight and health. Scand J Nutr 2005, 49:1520.

14. Foxcroft, L: Calories \& corsets: a history of dieting over 2,000 years. London: Profile Books; 2011.

15. Gilman SL: Diets and Dieting: A Cultural Encyclopedia. New York and London: Routledge; 2008.

16. Banting, W:. Letter on Corpulence, addressed to the public... with addenda. London: Harrison; 1869.

17. Silver HJ, Dietrich MS, Niswender KD: Effects of grapefruit, grapefruit juice and water preloads on energy balance, weight loss, body composition, and cardiometabolic risk in free-living obese adults. Nutr Metab (Lond) 2011, 8:8.

18. Stevens P: Grapefruit Diet. Scotts Valley, CA: CreateSpace Independent Publishing Platform; 2016.

19. Bailey DG, Malcolm J, Arnold O, Spence JD: Grapefruit Juice-Drug Interactions,” British J Clin Pharmacol 2004, 58: S831-S840.

20. Cerda JJ, Robbins FL, Burgin CW, Baumgartner TG, Rice RW: The effects of grapefruit pectin on patients at risk for coronary heart disease without altering diet or lifestyle. Clin Cardiol 1988, 11: 589-94.

21. Sun Y, Qiao L, Shen Y, Jiang P, Chen J, Ye X. Phytochemical Profile and Antioxidant Activity of Physiological Drop of Citrus Fruits. J Food Sci 2013, 78: C37-C42.

22. De Castro WV, Mertens-Talcott S, Rubner A, Butterweck V, Derendorf H: Variation of Flavonoids and Furanocoumarins in Grapefruit Juices: A Potential Source of Variability in Grapefruit Juice-Drug Interaction Studies. J Agricul Food Chem 2005, 54: 249-255.

23. Gattuso G, Barreca D, Gargiulli C, Leuzzi U, Caristi C: Flavonoid Composition of Citrus Juices. Molecules 2007, 12: 1641-1673.

24. Edwards DJ, Fitzsimmons ME, Schuetz EG, Yasuda K, Ducharme MP, Warbasse LH, et al.: 6',7'-Dihydroxybergamottinin Grapefruit Juice and Seville Orange Juice: Effects on Cyclosporine Disposition, Enterocyte CYP3A4, and P-Glycoprotein. Clin Pharm Therapeutics 1999, 65: 237-244.

25. Mulvihill EE, Allister EM, Sutherland BG, Telford DE, Sawyez CG, Edwards JY, et al.: Naringenin prevents dyslipidemia, apolipoprotein B overproduction, and hyperinsulinemia 
in LDL receptor-null mice with diet-induced insulin resistance. Diabetes 2009, 58:21982210.

26. Alam MA, Subhan N, Rahman MM, Uddin SJ, Reza HM, Sarker SD: Effect of citrus flavonoids, naringin and naringenin, on metabolic syndrome and their mechanisms of action. Adv Nutr 2014 14, 5:404-17.

27. Parhiz H, Roohbakhsh A, Soltani F, Rezaee R, Iranshahi M: Antioxidant and antiinflammatory properties of the citrus flavonoids hesperidin and hesperetin: an updated review of their molecular mechanisms and experimental models. Phytother Res 2015, 29:323-31.

28. Constantin RP, Constantin RP, Bracht A, Yamamoto NS, Ishii-Iwamoto EL, Constantin J: Molecular mechanisms of citrus flavanones on hepatic gluconeogenesis. Fitoterapia 2014, 92:148-62.

29. Goldwasser J, Cohen PY, Yang E, Balaguer P, Yarmush ML, Nahmias Y: Transcriptional regulation of human and rat hepatic lipid metabolism by the grapefruit flavonoid naringenin: role of PPARalpha, PPARgamma and LXRalpha. PLoS One 2010, 5:e12399.

30. Leray V, Freuchet B, Le Bloc'h J, Jeusette I, Torre C, Nguyen P:. Effect of citrus polyphenol- and curcumin-supplemented diet on inflammatory state in obese cats. $\mathrm{Br} \mathbf{J}$ Nutr 2011, 106 Suppl 1:S198-201.

31. Parafati M, Lascala A, Morittu VM, Trimboli F, Rizzuto A, Brunelli E, et al.: Bergamot polyphenol fraction prevents nonalcoholic fatty liver disease via stimulation of lipophagy in cafeteria diet-induced rat model of metabolic syndrome. J Nutr Biochem 2015, 26:93848.

32. Babish JG, Dahlberg CJ, Ou JJ, Keller WJ, Gao W, Kaadige MRet al.: Synergistic in vitro antioxidant activity and observational clinical trial of F105, a phytochemical formulation including Citrus bergamia, in subjects with moderate cardiometabolic risk factors. Can J Physiol Pharmacol 2016, 94: 1257-1266.

33. de la Garza AL, Etxeberria U, Haslberger A, Aumueller E, Martínez JA, Milagro FI: Helichrysum and Grapefruit Extracts Boost Weight Loss in Overweight Rats Reducing Inflammation. J Med Food 2015, 18:890-8.

34. Fujioka K, Greenway F, Sheard J, Ying Y: The effects of grapefruit on weight and insulin resistance: relationship to the metabolic syndrome. J Med Food 2006, 9:49-54.

35. Dallas C, Gerbi A, Elbez Y, Caillard P, Zamaria N, Cloarec M: Clinical Study to Assess the Efficacy and Safety of a Citrus Polyphenolic Extract of Red Orange, Grapefruit, and Orange (Sinetrol-XPur) on Weight Management and Metabolic Parameters in Healthy Overweight Individuals. Phytotherapy Research 2014, 28: 212-218.

36. Danbrot M: The New Cabbage Soup Diet. Blake: 2000.

37. USDA Food Composition Databases. [https://ndb.nal.usda.gov/]

38. Bahorun T, Luximon-Ramma A, Crozier A, Aruoma OI: Total phenol, flavonoid, proanthocyanidin and vitamin $\mathrm{C}$ levels and antioxidant activities of Mauritian vegetables. $\mathrm{J}$ Sci Food Agricul 2004, 84:1553-1561.

39. Qiu X, Gao DH, Xiang X, Xiong YF, Zhu TS, Liu LG, et al.: Ameliorative effects of lutein on non-alcoholic fatty liver disease in rats. World J Gastroenterol 2015, 21:8061-72. 
40. Xiao J, Wang J, Xing F, Han T, Jiao R, Liong EC, et al.: Zeaxanthin dipalmitate therapeutically improves hepatic functions in an alcoholic fatty liver disease model through modulating MAPK pathway. PLoS One 2014, 9:e95214.

41. Kobayasi R, Akamine EH, Davel AP, Rodrigues MA, Carvalho CR, Rossoni LV: Oxidative stress and inflammatory mediators contribute to endothelial dysfunction in highfat diet-induced obesity in mice. J Hypertens 2010, 28:2111-9.

42. Lee S, Kim YJ, Kwon S, Lee Y, Choi SY, Park J, Kwon HJ: Inhibitory effects of flavonoids on TNF- $\alpha$-induced IL-8 gene expression in HEK 293 cells. BMB Reports 2009, 42: 265270.

43. Cruz KJ, de Oliveira AR, Morais JB, Severo JS, Marreiro DD: Role of microRNAs on adipogenesis, chronic low-grade inflammation, and insulin resistance in obesity. Nutrition 2017, 35: 28-35.

44. Kowalski J, Samojedny A, Paul M, Pietsz G, Wilczok T: Effect of apigenin, kaempferol and resveratrol on the expression of interleukin-1 $\beta$ and tumor necrosis factor- $\alpha$ genes in J774.2 macrophages. Pharmacol Reports 2005, 57:390-4.

45. Cortes JR, Perez-G M, Rivas MD, Zamorano J: Kaempferol Inhibits IL-4-Induced STAT6 Activation by Specifically Targeting JAK3. J Immunol 2007, 179: 3881-3887.

46. Henagan TM, Cefalu WT, Ribnicky DM et al.: In vivo effects of dietary quercetin and quercetin-rich red onion extract on skeletal muscle mitochondria, metabolism, and insulin sensitivity. Genes Nutr 2015, 10: 451.

47. Moon J, Do HJ, Kim OY, Shin MJ: Antiobesity effects of quercetin-rich onion peel extract on the differentiation of 3T3-L1 preadipocytes and the adipogenesis in high fat-fed rats. Food Chem Toxicol 2013, 58: 347-354.

48. Gao M, Ma Y, Liu D: Rutin suppresses palmitic acids triggered inflammation in macrophages and blocks high fat diet-induced obesity and fatty liver in mice. Pharm Res 2013, 30:2940-2950.

49. Le NH, Kim C-S, Park T, et al.: Quercetin protects against obesity-induced skeletal muscle inflammation and atrophy. Mediators Inflamm 2014, 2014: 834294.

50. Arias N, Macarulla MT, Aguirre L, Martínez-Castaño MG, Portillo MP: Quercetin can reduce insulin resistance without decreasing adipose tissue and skeletal muscle fat accumulation. Genes Nutr 2014, 9: 361.

51. Feng X, Weng D, Zhou F, Owen YD, Qin H, Zhao J, et al.: Activation of PPAR $\gamma$ by a Natural Flavonoid Modulator, Apigenin Ameliorates Obesity-Related Inflammation Via Regulation of Macrophage Polarization. E Bio Medicine 2016, 9: 61-76.

52. Jung UJ, Cho YY, Choi MS: Apigenin Ameliorates Dyslipidemia, Hepatic Steatosis and Insulin Resistance by Modulating Metabolic and Transcriptional Profiles in the Liver of High-Fat Diet-Induced Obese Mice. Nutrients 2016, 8.

53. Aiso I, Inoue H, Seiyama Y, Kuwano T: Compared with the intake of commercial vegetable juice, the intake of fresh fruit and komatsuna (Brassica rapa L. var. perviridis) juice mixture reduces serum cholesterol in middle-aged men: a randomized controlled pilot study. Lipids Health Dis 2014, 13:102.

54. Allison DB, Antoine LH, George BJ: Incorrect statistical method in parallel-groups RCT led to unsubstantiated conclusions. Lipids Health Dis 2016, 15:77. 
55. Holt SH, Miller JC, Petocz P, Farmakalidis E: A satiety index of common foods. Eur J Clin Nutr 1995, 49:675-90.

56. Yadav PR: Endocrinology. New Delhi: Discovery Publishing House; 2004.

57. Simeons ATW: The action of chorionic gonadotropin in the obese. Lancet 1954, 2: 946947.

58. Stein MR, Julis RE, Peck CC, Hinshaw W, Sawicki JE, Deller JJ: Ineffectiveness of human chorionic gonadotropin in weight reduction: a small double-blind study. Am J Con Nutr 1976, 29: 940-8.

59. Russell SE: hCG Diet 800 Calorie Protocol. 2nd Ed. Trinity, FL: HCG Doctors Group LLC; 2012.

60. Wright YL: Secrets about the HCG Diet. USA: Lulu.com; 2012.

61. Butler SA, Cole LA: Evidence for, and Associated Risks with, the Human Chorionic Gonadotropin Supplemented Diet. J Diet Suppl 2016, 13: 694-9.

62. Sun J, Chen P: Ultra high-performance liquid chromatography with high-resolution mass spectrometry analysis of African mango (Irvingia gabonensis) seeds, extract, and related dietary supplements. J Agric Food Chem 2012, 60:8703-9.

63. Onakpoya I, Davies L, Posadzki P, Ernst E: The efficacy of Irvingia gabonensis supplementation in the management of overweight and obesity: a systematic review of randomized controlled trials. J Diet Suppl 2013, 10:29-38.

64. Behl T, Kotwani A: Chinese herbal drugs for the treatment of diabetic retinopathy. J Pharm Pharmacol 2017, 69: 223-235.

65. Mao XQ, Yu F, Wang N, Wu Y, Zou F, Wu K, et al.: Hypoglycemic effect of polysaccharide enriched extract of Astragalus membranaceus in diet induced insulin resistant C57BL/6J mice and its potential mechanism. Phytomedicine 2009, 16:416-25.

66. Araujo TR, Freitas IN, Vettorazzi JF, Batista TM, Santos-Silva JC, Bonfleur ML, et al.: Benefits of L-alanine or L-arginine supplementation against adiposity and glucose intolerance in monosodium glutamate-induced obesity. Eur J Nutr 2016, 1-12.

67. Clemmensen C, Madsen AN, Smajilovic S, Holst B, Bräuner-Osborne H: L-Arginine improves multiple physiological parameters in mice exposed to diet-induced metabolic disturbances. Amino Acids 2012, 43:1265-75.

68. Laviano A, Molfino A, Lacaria MT, Canelli A, De Leo S, Preziosa I, Rossi FF.: Glutamine supplementation favors weight loss in nondieting obese female patients. A pilot study. Eur J Clin Nutr 2014, 68:1264-6.

69. de Souza AZ, Zambom AZ, Abboud KY, Reis SK, Tannihão F, Guadagnini D, et al.: Oral supplementation with L-glutamine alters gut microbiota of obese and overweight adults: A pilot study. Nutrition 2015, 31: 884-9.

70. Pooyandjoo M, Nouhi M, Shab-Bidar S, Djafarian K, Olyaeemanesh A: The effect of (L-) carnitine on weight loss in adults: a systematic review and meta-analysis of randomized controlled trials. Obes Rev 2016, 17:970-6.

71. Knight BA, Shields BM, Brook A, Hill A, Bhat DS, Hattersley AT, Yajnik CS: Lower Circulating B12 Is Associated with Higher Obesity and Insulin Resistance during Pregnancy in a Non-Diabetic White British Population. PLoS One, 2015: 10:e0135268. 
72. Westphal S, Borucki K, Taneva E, Makarova R, Luley C. Extended-release niacin raises adiponectin and leptin. Atherosclerosis 2007, 193: 361-5.

73. Chen L, So WY, Li SY, Cheng Q, Boucher BJ, Leung PS: Niacin-induced hyperglycemia is partially mediated via niacin receptor GPR109a in pancreatic islets. Mol Cell Endocrinol.2015, 404:56-66.

74. Couturier A, Ringseis R, Most E, Eder K: Pharmacological doses of niacin stimulate the expression of genes involved in carnitine uptake and biosynthesis and improve the carnitine status of obese Zucker rats. BMC Pharmacol Toxicol 2014, 15: 37.

75. Lijesen GK, Theeuwen I, Assendelft WJ, Van Der Wal G: The effect of human chorionic gonadotropin (HCG) in the treatment of obesity by means of the Simeons therapy: a criteria-based meta-analysis. Br J Clin Pharmacol 1995, 40:237-43.

76. Toffle RC: "There they go again"--hCG and weight loss. WV Med J 2011, 107: 12-3. 